University of Nebraska - Lincoln

DigitalCommons@University of Nebraska - Lincoln

$1-1-2001$

\title{
CoPtCr:C nanocomposite films for high density recording
}

H. Zeng

University of Nebraska - Lincoln

M.L. Yan

University of Nebraska - Lincoln

Yi Liu

University of Nebraska-Lincoln, yliu@unl.edu

David J. Sellmyer

University of Nebraska-Lincoln, dsellmyer@unl.edu

Follow this and additional works at: https://digitalcommons.unl.edu/physicssellmyer

Part of the Physics Commons

Zeng, H.; Yan, M.L.; Liu, Yi; and Sellmyer, David J., "CoPtCr:C nanocomposite films for high density recording" (2001). David Sellmyer Publications. 51.

https://digitalcommons.unl.edu/physicssellmyer/51

This Article is brought to you for free and open access by the Research Papers in Physics and Astronomy at DigitalCommons@University of Nebraska - Lincoln. It has been accepted for inclusion in David Sellmyer Publications by an authorized administrator of DigitalCommons@University of Nebraska - Lincoln. 


\title{
CoPtCr:C nanocomposite films for high density recording
}

\author{
H. Zeng ${ }^{\text {a) }}$ and M. L. Yan \\ Center for Materials Research and Analysis and Department of Physics and Astronomy, \\ University of Nebraska, Lincoln, Nebraska 68588 \\ Y. Liu \\ Center for Materials Research and Analysis and Department of Mechanical Engineering, \\ University of Nebraska, Lincoln, Nebraska 68588 \\ D. J. Sellmyer \\ Center for Materials Research and Analysis and Department of Physics and Astronomy, \\ University of Nebraska, Lincoln, Nebraska 68588
}

(Received 8 June 2000; accepted for publication 16 October 2000)

\begin{abstract}
We report results on the magnetic properties of nanocomposite films of the form $\left(\mathrm{Co}_{86} \mathrm{Cr}_{14}\right)_{x} \mathrm{Pt}_{1-x}: \mathrm{C}$, which were prepared by magnetron sputtering and subsequent annealing. $\mathrm{X}$-ray diffraction shows that these films consist of $\mathrm{CoPtCr}$ grains with the face-centered-tetragonal structure embedded in an amorphous $\mathrm{C}$ matrix. Magnetic properties such as coercivity $\left(H_{c}\right)$, remanence ratio $(S)$, and coercive squareness $\left(S^{*}\right)$ are strongly dependent on the Pt and $\mathrm{C}$ composition and annealing temperatures. Compared with previously reported $\mathrm{CoPt}: \mathrm{C}$ films with a equiatomic Co and $\mathrm{Pt}$ ratio, lower exchange coupling and higher $S$ and $S^{*}$ at the same $\mathrm{C}$ concentration were obtained. $H_{c}$ values ranging from 2 to $10 \mathrm{kOe}$ and $S$ close to 1 were achieved for film thicknesses down to $10 \mathrm{~nm}$. These features make CoPtCr:C nanocomposite films very attractive for next-generation high-density recording. (C) 2001 American Institute of Physics.

[DOI: 10.1063/1.1331643]
\end{abstract}

High anisotropy materials with magnetically isolated grains below $10 \mathrm{~nm}$ are required to retain adequate signalto-noise ratio and thermal stability for future high density recording media $\left(>100 \mathrm{~Gb} / \mathrm{in}^{2}\right) .{ }^{1}$ Most recently, nanocomposite films with $\mathrm{L}_{0}$ structured $\mathrm{CoPt}$ and FePt nanoparticles imbedded in nonmagnetic matrix have received considerable attention. ${ }^{2,3}$ These films possess high magnetocrystalline anisotropy $\left(K_{u}>3 \times 10^{7} \mathrm{erg} / \mathrm{cm}^{3}\right)$, from which high coercivity $\left(H_{c} \geqslant 5 \mathrm{kOe}\right)$ and thermal stability $\left(K_{u} V / k_{B} T \geqslant 60\right.$, where $V$ is the grain volume) can be obtained. ${ }^{2}$ At the same time, the matrix materials isolate the magnetic grains and restrict the growth of grains. As a result, small intergranular interactions and grain sizes are obtained. Results on nanocomposite films such as $\mathrm{CoPt}: \mathrm{ZrO}_{x},{ }^{4} \mathrm{CoPt}: \mathrm{C},{ }^{2} \mathrm{CoPt}: \mathrm{B},{ }^{5} \mathrm{CoPt}: \mathrm{Ag},{ }^{3}$ and FePt: $\mathrm{SiO}_{2}$, (Ref. 6) have been reported. Grain sizes below 5 $\mathrm{nm}$ have been achieved in FePt: $\mathrm{B}_{2} \mathrm{O}_{3}$ films. ${ }^{7}$ Recording performance also has been studied. ${ }^{4}$ However, a high concentration of nonmagnetic matrix material could deteriorate magnetic and recording properties, which will be discussed below. On the other hand, it is well-known that in conventional $\mathrm{Co}$ alloy media, $\mathrm{Cr}$ rich regions forming at grain boundaries are found to reduce exchange coupling, resulting in lower media noise. ${ }^{8}$ Therefore it might be expected that similar segregation mechanism would work in Cr-doped fct CoPt films. In this study, $\left(\mathrm{Co}_{86} \mathrm{Cr}_{14}\right)_{x} \mathrm{Pt}_{1-x}$ : $\mathrm{C}$ nanocomposite films were prepared and studied. $\mathrm{Cr}$ was introduced to suppress intergranular interactions so that lower $\mathrm{C}$ concentration might be needed to decouple grains. Compared with previously studied CoPt:C films, ${ }^{2}$ these films have improved magnetic properties as measured by $\delta M, S$, and $S^{*}$.

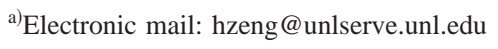

$\left(\mathrm{Co}_{86} \mathrm{Cr}_{14}\right)_{x} \mathrm{Pt}_{1-x} / \mathrm{C}$ multilayers were prepared by magnetron sputtering onto $\mathrm{Si}(100)$ substrates. The base pressure was less than $3 \times 10^{-7}$ Torr and the working Ar pressure was 3 mTorr. The Pt atomic composition was varied from 30 to 45; C concentration was varied from $0 \%$ to $50 \%$ volume fraction. Film thickness ranged from 10 to $20 \mathrm{~nm}$. All the films were annealed at 600,650 , and $700{ }^{\circ} \mathrm{C}$, respectively, for half an hour to produce the $\mathrm{CoPtCr}: \mathrm{C}$ nanocomposite. The structural properties were characterized by $\mathrm{x}$-ray diffraction. Magnetic properties were measured by alternatinggradient-force and superconducting quantum interference device (SQUID) magnetometers. All the coercivities measured are in-plane unless otherwise specified.

All as-deposited films show that the magnetic alloy has a disordered face-centered-cubic (fcc) structure with (111) texture. Small-angle x-ray diffraction reveals a multilayer structure for these films. After annealing, the films undergo a phase transition from disordered fcc to ordered fct, with the $\mathrm{C}$ matrix being amorphous, which is similar to the behavior of previously studied CoPt:C films. ${ }^{2}$ However, there is a significant difference between the $\mathrm{x}$-ray diffraction pattern of CoPtCr:C and CoPt:C films. All CoPtCr:C films show (111) texture, while for $\mathrm{CoPt}: \mathrm{C}$ films, CoPt grains are randomly orientated. Figure 1(a) shows the x-ray diffraction (XRD) pattern for a $20 \mathrm{~nm}\left(\mathrm{Co}_{86} \mathrm{Cr}_{14}\right)_{60} \mathrm{Pt}_{40}$ film without $\mathrm{C}$ matrix and annealed at $650{ }^{\circ} \mathrm{C}$. Only the (111) and (222) peaks are visible. On the contrary, from the inset of Fig. 1(a) we see that all peaks show up in the XRD pattern of the CoPt film prepared under the same conditions. When $\mathrm{C}$ matrix is present, as can be seen from Fig. 1(b), the XRD peak intensity drops dramatically accompanying the broadening of the peaks. (111) texture is present for all $\mathrm{C}$ concentrations. 

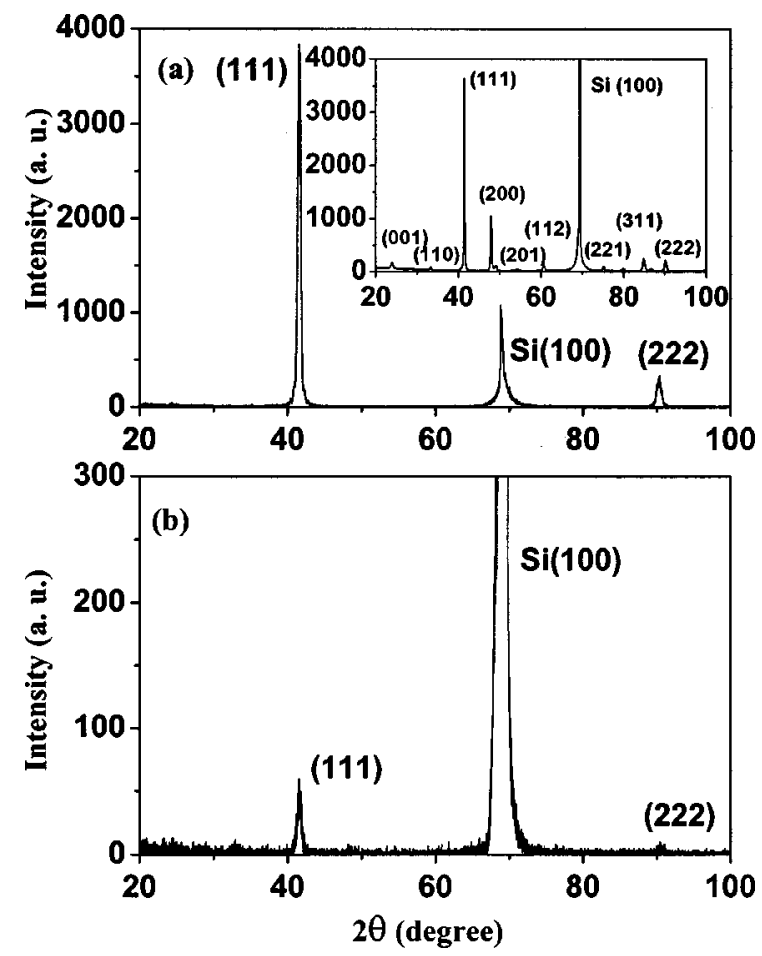

FIG. 1. XRD pattern of (a) a $20 \mathrm{~nm}$ thick $\left(\mathrm{Co}_{86} \mathrm{Cr}_{14}\right)_{60} \mathrm{Pt}_{40}$ film, (inset) a 20 $\mathrm{nm} \mathrm{Co}{ }_{50} \mathrm{Pt}_{50}$ film and (b) a $20 \mathrm{~nm} \mathrm{CoCrPt} \mathrm{C}$ with 40 vol \% C annealed at $650{ }^{\circ} \mathrm{C}$ for $30 \mathrm{~min}$.

CoPtCr grain size calculated from Scherrer's formula ranges from 10 to $20 \mathrm{~nm}$, and decreases rapidly with increasing $\mathrm{C}$ concentration. Transmission electron microscopy (TEM) plan view of a typical sample with $40 \mathrm{vol} \% \mathrm{C}$ annealed at $650{ }^{\circ} \mathrm{C}$ is shown in Fig. 2. The average grain size is about 7 to $8 \mathrm{~nm}$, with some grains agglomerated.

All as-deposited films are magnetically soft, with coercivities less than 50 Oe. $H_{c}$ of the annealed films is strongly dependent on $\mathrm{Pt}$ and $\mathrm{C}$ compositions and annealing temperatures. Figure 3 shows the coercivity of $\left(\mathrm{Co}_{86} \mathrm{Cr}_{14}\right)_{60} \mathrm{Pt}_{40}: \mathrm{C}$, with a thickness of $15 \mathrm{~nm}, \mathrm{C}$ concentration ranging from 0 to $50 \mathrm{vol} \%$, and annealing temperatures at 600,650 , and $700{ }^{\circ} \mathrm{C}$, respectively. At fixed annealing temperature, coercivity first increases slightly when $10 \% \mathrm{C}$ matrix is added.

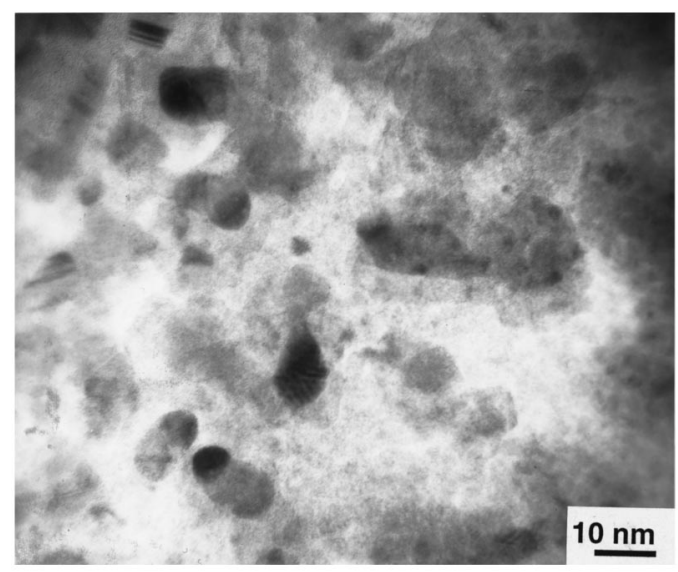

FIG. 2. TEM plan view of a $20 \mathrm{~nm}$ thick $\left(\mathrm{Co}_{86} \mathrm{Cr}_{14}\right)_{60} \mathrm{Pt}_{40}$ :C, with 40 vol \% $\mathrm{C}$ annealed at $650^{\circ} \mathrm{C}$.

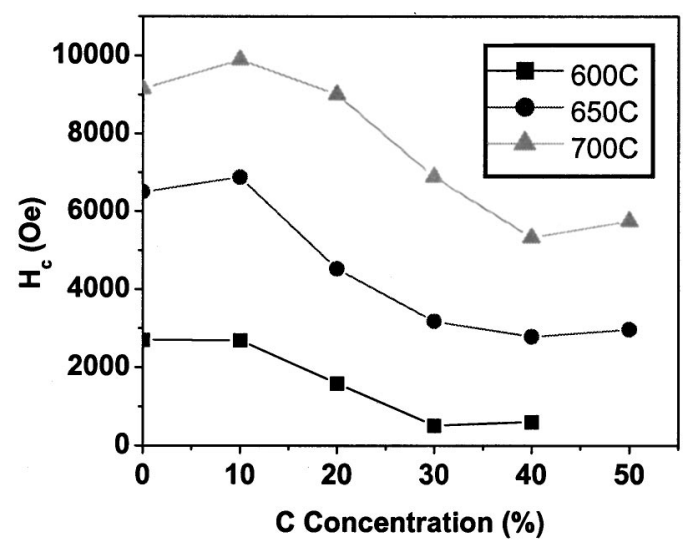

FIG. 3. $H_{c}$ as a function of $\mathrm{C}$ concentration for $15 \mathrm{~nm}\left(\mathrm{Co}_{86} \mathrm{Cr}_{14}\right)_{60} \mathrm{Pt}_{40}$ :C annealed at 600,650 , and $700{ }^{\circ} \mathrm{C}$, respectively.

This may be due to the addition of $\mathrm{C}$, which isolates the grains, reducing exchange coupling. The addition of $\mathrm{C}$ may also increase pinning sites. Further increase of $\mathrm{C}$ concentration results in the rapid decrease of $H_{c}$. The most probable explanation may be that the presence of $\mathrm{C}$ hinders the formation of the ordered fct phase, thus decreasing anisotropy. Excessive $\mathrm{C}$ also tends to suppress the growth of magnetic grains.

It is seen clearly that coercivity increases dramatically with annealing temperature. For the three curves shown in Fig. 3, the peak values of $H_{c}$ at around $10 \% \mathrm{C}$ concentration increase from 2700 to 6900 to 10000 Oe for annealing temperatures at 600,650 , and $700{ }^{\circ} \mathrm{C}$, respectively. This is closely related to the formation of the $\mathrm{L}_{0}$ phase. Ristau et al. found that there is a direct relationship between $H_{c}$ and volume fraction of the ordered phase, therefore annealing temperatures. ${ }^{9}$ This seems to be also true for both CoPt:C and $\mathrm{CoPtCr}: \mathrm{C}$ nanocomposite films.

Pt composition also plays a crucial role in determining the coercivity. As shown in Fig. 4, when Pt composition increases from $30 \%$ to $40 \%, H_{c}$ generally increases. $H_{c}$ decreases when Pt reaches $45 \%$. For pure CoPt, anisotropy and coercivity usually reach maxima near the equiatomic compo-

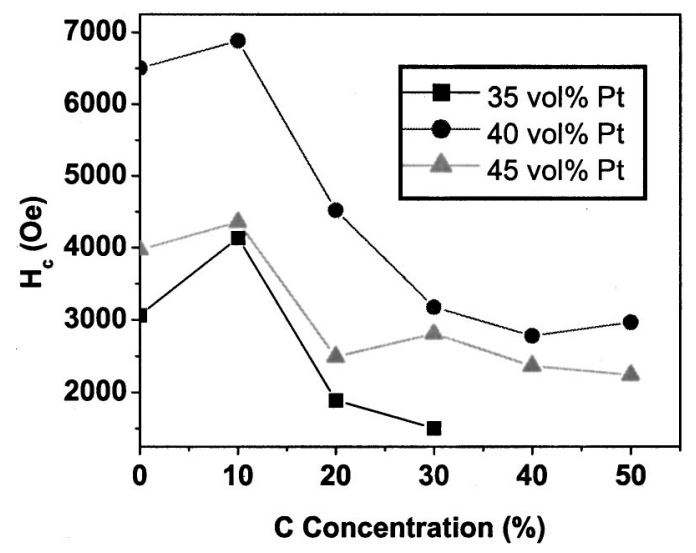

FIG. 4. $H_{c}$ as a function of $\mathrm{C}$ concentration for $15 \mathrm{~nm}\left(\mathrm{Co}_{86} \mathrm{Cr}_{14}\right)_{1-x} \mathrm{Pt}_{x}: \mathrm{C}$ annealed at $650^{\circ} \mathrm{C}$, and $x=35,40$, and 45 , respectively. 


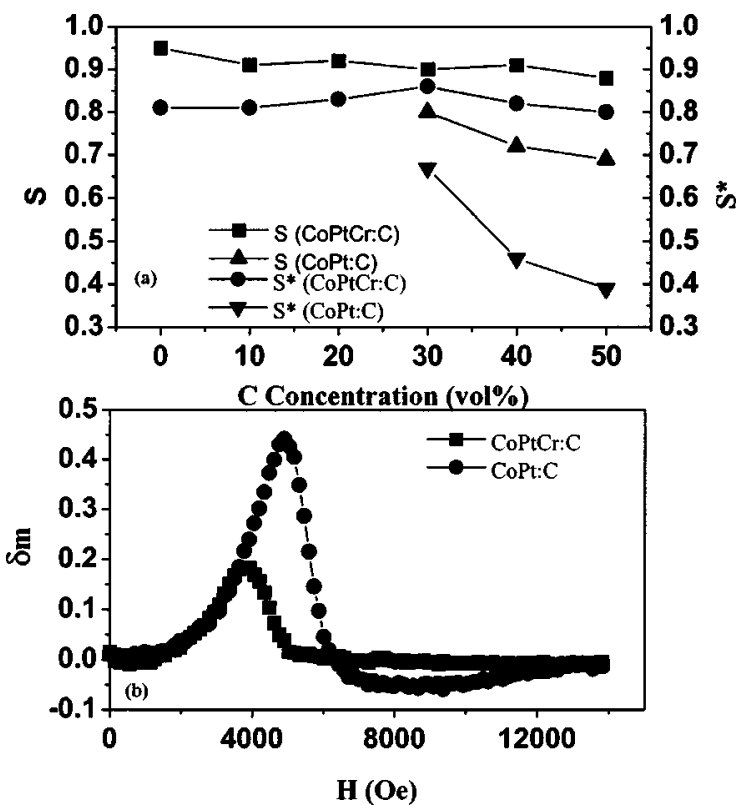

FIG. 5. (a) $S$ and $S^{*}$ of CoPtCr:C and CoPtCr prepared at the same annealing conditions at various $\mathrm{C}$ concentrations. (b) $\delta m$ plot for a typical CoPtCr:C sample and a CoPt:C sample, with $10 \% \mathrm{C}$ concentration.

sition. The fact that the coercivity of $\mathrm{CoPtCr}: \mathrm{C}$ films reaches its maximum at $\sim 40 \% \mathrm{Pt}$ seems to indicate that part of Co is alloyed with $\mathrm{Cr}$.

In this study, $\mathrm{Cr}$ was introduced originally to further reduce the intergranular interactions. Other effects of $\mathrm{Cr}$ doping on magnetic properties are also discovered. Figure 5 compares the remanence ratio $S$, coercive squareness $S^{*}$, and $\delta m$ of $\mathrm{CoPt}: \mathrm{C}$ and $\mathrm{CoPtCr}: \mathrm{C}$ films prepared at similar conditions. $\delta m$ is defined as $m_{d}-\left(1-2 m_{r}\right)$, where $m_{d}$ and $m_{r}$ are reduced dc remanence and isothermal remanence, respectively. ${ }^{10} \delta m$ is a qualitative measurement of the intergranular interactions. It is seen from Fig. 5(a) that: (a) For CoPtCr:C films, $S$ and $S^{*}$ remain largely unchanged for C concentrations varying between 0 and 50\%, while for CoPt:C films, $S$ and $S^{*}$ decrease with C concentration rapidly. (b) $S$ and $S^{*}$ of $\mathrm{CoPtCr}$ :C films are significantly higher than that of CoPt:C at the same C concentrations. An increase in $S^{*}$ is also reported in $\mathrm{CoCr} / \mathrm{Pt}$ multilayer films without significant effect in the signal-to-noise ratio. ${ }^{11}$ It is likely that the higher $S$ comes from some in-plane texture, and the higher $S^{*}$ may come from more uniform grain size distribution than previously reported CoPt:C films. Further study is ongoing to clarify the role of $\mathrm{Cr}$ in improving $S$ and $S^{*}$. For application purposes, high $S$ is desired to give adequate signal output without sacrificing resolution as thickness goes down; a reasonably high $S^{*}$ is desired for signal output, writability, and narrow transitions, provided that the grains are exchange decoupled. ${ }^{12}$

The $\delta m$ peak values generally decrease with increasing $\mathrm{C}$ concentrations, which is to be expected, since more $\mathrm{C}$ isolates grains better. It is observed that $\delta m$ peak values are lower for CoPtCr:C films than for CoPt:C films with the same $\mathrm{C}$ concentration. Figure 5(b) shows $\delta m$ curves for a typical CoPtCr:C sample and a CoPt:C sample prepared under similar conditions. The $\mathrm{C}$ concentration is $10 \%$ in both cases. The peak value for $\mathrm{CoPtCr}: \mathrm{C}$ film is close to +0.2 , which is much lower than that of CoPt:C. This result means that with the addition of $\mathrm{Cr}$, less $\mathrm{C}$ is able to decouple the grains. From the TEM image, we can see that some grains look agglomerated. However, $\delta M$ measurements indicate very weak exchange coupling. This suggests that some $\mathrm{Cr}$ may go into grain boundaries and make grains magnetically decoupled. As mentioned above, higher $\mathrm{C}$ concentration could deteriorate magnetic and recording properties. Previous studies on CoPt:C show that $H_{c}$ and $S$ decrease rapidly with increasing $\mathrm{C}$ concentration. On the other hand, higher $\mathrm{C}$ concentration leads to fewer magnetic grains per unit volume, which eventually could result in higher dc noise. Therefore CoPtCr:C films may be superior to CoPt:C in the sense that they show much lower interactions at low $\mathrm{C}$ concentration, where the magnetic properties are also optimal.

In summary, we have prepared CoPtCr:C nanocomposite films with high anisotropy and magnetic properties which can be tailored to fit the requirements of magnetic recording media. Compared with $\mathrm{CoPt}: \mathrm{C}$ films, higher remanence ratio and coercive squareness are produced. Furthermore, a much lower exchange coupling is found in $\mathrm{CoPtCr}: \mathrm{C}$ films than in $\mathrm{CoPt}: \mathrm{C}$ films at the same $\mathrm{C}$ concentrations. These improved features make CoPtCr:C very attractive for next-generation high-density recording.

The authors thank C. P. Luo and Dr. M. J. Yu for fruitful discussions. This research is supported by NSF, IBM, NRI, and CMRA.

${ }^{1}$ D. J. Sellmyer, M. Yu, and R. D. Kirby, Nanostruct. Mater. 12, 1021 (1999).

${ }^{2}$ M. Yu, Y. Liu, and D. J. Sellmyer, Appl. Phys. Lett. 75, 3992 (1999).

${ }^{3}$ S. Stavroyiannis, I. Panagiotopoulos, D. Niarchos, J. A. Christodoulides, Y. Zhang, and G. C. Hadjipanayis, J. Appl. Phys. 85, 4304 (1999).

${ }^{4}$ K. R. Coffey, M. A. Parker, and J. K. Howard, IEEE Trans. Magn. 31, 2737 (1995).

${ }^{5}$ N. Li, B. M. Lairson, and O. Kwon, J. Magn. Magn. Mater. 205, 1 (1999).

${ }^{6}$ C. P. Luo and D. J. Sellmyer, Appl. Phys. Lett. 75, 3162 (1999).

${ }^{7}$ C. P. Luo, Y. Liu, and D. J. Sellmyer, Appl. Phys. Lett. (submitted).

${ }^{8}$ M. R. Kim, S. Guruswamy, and K. E. Johnson, IEEE Trans. Magn. 29, 2673 (1993).

${ }^{9}$ K. R. Coffey, M. A. Parker, and J. K. Howard, IEEE Trans. Magn. 31, 2737 (1995)

${ }^{10}$ P. E. Kelly, K. O'Grady, P. I. Mayo, and R. W. Chantrell, IEEE Trans. Magn. 25, 3881 (1989).

${ }^{11}$ K. Takano, G. Zeltzer, D. K. Weller, and E. E. Fullerton, J. Appl. Phys. 87, 6364 (2000).

${ }^{12}$ K. E. Johnson, Noise in Digital Magnetic Recording, edited by T. C. Arnoldussen and L. L. Nunnelley (World Scientific, Singapore, 1992), Chap. 2. 